\begin{tabular}{lr}
\hline \multicolumn{1}{c}{ D Y N A M I C E C O N O M E T R I C } & M O D E L S \\
DOI: http://dx.doi.org/10.12775/DEM.2015.002 & Vol. 15 (2015) 27-47 \\
\hline $\begin{array}{l}\text { Submitted October 25, 2015 } \\
\text { Accepted December 15, 2015 }\end{array}$ & ISSN (online) 2450-7067 \\
ISSN (print) 1234-3862
\end{tabular}

\title{
Discrete Spectral Analysis. The Case of Industrial Production in Selected European Countries**
}

\begin{abstract}
A b s tract. The aim of this paper is to show the usefulness the discrete spectral analysis in identification cyclical fluctuations. The subsampling procedure was applied to construct the asymptotically consistent test for Fourier coefficient and frequency significance. The case of monthly production in industry in European countries (thirty countries) was considered. Using proposed approach the frequencies concerning business fluctuations, seasonal fluctuations and trading-day effects fluctuations were recognized in considered data sets. The comparison with existing procedures was shown.
\end{abstract}

K e y w or d s: discrete spectral analysis, almost periodic function, frequency identification, graphical test.

J E L Classification: C14, C46, E32.

\section{Introduction}

The main part of monthly or quarterly macroeconomic time series concerning industry, trade, service, national accounts, prices, etc. exhibit both: seasonal fluctuations and business cycle fluctuations. The problem of analysing these cyclical fluctuations is widely considered in the literature using different statistical tools. One popular nonparametric approach is based on a spectral analysis.

\footnotetext{
* Correspondence to Łukasz Lenart, Cracow University of Economics, Department of Mathematics, e-mail: lenartl@uek.krakow.pl

** This research was supported by Research Grant DEC-2013/09/B/HS4/01945 from the National Science Centre

(C) 2015 Nicolaus Copernicus University Press. All rights reserved.

http://www.dem.umk.pl/dem
} 
The spectral analysis of macroeconomic time series is considered mainly in continuous counterpart (see Ftiti, 2010; Metz, 2009; Orlov, 2006; Orlov, 2009; Pakko, 2004; McAdam and Mestre, 2008; Uebele and Ritschl, 2009). Under stationarity assumption the continuous function called spectral density function is defined. Based on spectral density function (and the definition of harmonizable time series) the popular spectral characteristics are defined: modulus of coherency function, dynamic correlation, dynamic correlation on a frequency band, cohesion, cohesion within the frequency band, phase shift (see Priestley, 1981; Hamilton, 1994; Croux, 2001 for more details). These measures are broadly used in analysing the business cycle fluctuations. They are estimated under fundamental assumption that time series is zero mean. But this assumption is not supported by any formal statistical test in most empirical macroeconomic real data analysis.

In this paper the more general assumption is formulated concerning nontrivial mean function. This general assumption was considered in Lenart, 2011; Lenart and Pipień, 2013a; Lenart and Pipień, 2013b (in univariate case) and recently in Lenart and Pipien, 2015 (in multivariate case) with application to macroeconomic time series. In this paper we show that the parameters of the discrete spectrum can be identified not only with the seasonal and business cycle fluctuations but additionally with the trading-day effect.

In the section 2, based on Lenart and Pipień, 2013a and Lenart and Pipien, 2015 the model was formulated and illustrative example was presented. In the next part the empirical analysis was presented. The production in industry - monthly data (mining and quarrying; manufacturing; electricity, gas, steam and air conditioning supply) from Feb. 2000 to Dec. 2014 was considered. In the first subsection the graphical methods to identify/recognize the frequency (concerning to business fluctuations, seasonal fluctuations and trading-day effect fluctuations) was presented. Such graphical methods to identify 'periodic phenomena' in the autocovariance function in class of Almost Periodically Correlated time series were presented in Hurd and Gerr, 1991 and recently in Lenart, 2011. Finally in the second subsection formal statistical test for frequency significance was applied to data sets.

\section{Model specification}

Let $Y_{t}$ be macroeconomic time series (index, gross data) with possible: seasonal fluctuations with period $T$, business fluctuations and trading-day 
fluctuations. Let us denote the natural logarithm: $\tilde{Y}_{t}=\ln \left(Y_{t}\right)$. Based on Lenart and Pipień, 2013a we assume that

$$
E\left(\tilde{Y}_{t}\right)=f(t, \beta)+\mu(t),
$$

where $\mu(t)$ is almost periodic function (ap in short) of the form $\mu(t)=\sum_{\psi \in \Psi} m(\psi) e^{i \psi t}$, where

$$
m(\psi)=\lim _{n \rightarrow \infty} \frac{1}{n} \sum_{t=1}^{n} \mu(t) e^{-i \psi t} .
$$

We assume that the set of frequencies $\Psi=\{\psi \in[0,2 \pi):|m(\psi)| \neq 0\}$ is finite and unknown. This set $\Psi$ can be decompose in natural way via: $\Psi=\Psi_{1} \cup \Psi_{2} \cup \Psi_{3}$, where $\Psi_{1}$ corresponds to business fluctuations, $\Psi_{2} \subset\{2 k \pi d T, k=0,1, T-1\}$ corresponds to seasonal fluctuations and $\Psi_{3}$ is a set of remaining frequencies (corresponding to interaction between seasonal and business fluctuations and frequencies corresponding to trading-day effects). Equivalently, the model (1) can be written via:

$$
E\left(\tilde{Y}_{t}\right)=f(t, \beta)+\mu_{1}(t)+\mu_{2}(t),
$$

where $\mu_{1}(t)$ is a periodic function with period $T$ which represents the seasonal fluctuations and $\mu_{2}(t)=\sum_{\psi \in \Psi \backslash \Psi_{2}} m(\psi) e^{i \psi t}$. The function $\mu_{1}(t)$ can be equivalently represented by the vector (sequence of seasonal values) $\boldsymbol{\mu}=\left[\mu_{1} \mu_{2} \ldots \mu_{T-1}\right]^{\prime}$, and $\mu_{T}=-\left(\mu_{1}+\mu_{2}+\ldots+\mu_{T-1}\right)$.

The sequence $X_{t}=\tilde{Y}_{t}-\tilde{Y}_{t-1}$ represents the monthly log growth rate. If $f(t, \beta)$ is a polynomial of order one then

$$
E\left(X_{t}\right)=\tilde{\mu}_{1}(t)+\tilde{\mu}_{2}(t)
$$

where $\tilde{\mu}_{1}(t)=\mu_{1}(t)-\mu_{1}(t-1)$ is periodic function that corresponds to seasonal pattern and $\tilde{\mu}_{2}(t)=\mu_{2}(t)-\mu_{2}(t-1)=\sum_{\psi \in \Psi \backslash \Psi_{2}} \tilde{m}(\psi) e^{i \psi t}$. The sequence $X_{t}^{\prime}=\tilde{Y}_{t}-\tilde{Y}_{t-1}$ represents the annual log growth rate. If $f(t, \beta)$ is a polynomial of order one then

$$
E\left(X_{t}^{\prime}\right)=\tilde{\mu}_{2}^{\prime}(t)
$$


where $\tilde{\mu}_{2}^{\prime}(t)=\mu_{2}(t)-\mu_{2}(t-12)=\sum_{\psi \in \Psi \backslash \Psi_{2}} \tilde{m}^{\prime}(\psi) e^{i \psi t}$. In future work we assume that the autocovariance function of the time series $\left\{X_{t}: t \in Z\right\}$ (or $\left.\left\{X_{t}^{\prime}: t \in Z\right\}\right)$ is a periodic function with the same period $T$. This is a natural generalization of the assumption concerning second order stationarity. This assumption follows from the natural hypothesis that for monthly data at some months the variability can be higher than at another month. With no loss of generality we assume that exists natural $m$ such that $n=m s$. Then the time series $\left\{X_{t}: t \in Z\right\}$ can be represented as a second order stationary $T$ -valued time series with almost periodic mean function. More precisely the time series $Y_{t}=\left[X_{1+(t-1) s} X_{2+(t-1) s} \ldots X_{t s}\right]^{T}$ is $T$ values second order stationary time series with almost periodic mean function. This mean function can be decomposed (in natural way) to two main parts: periodic function (that corresponds to seasonal frequencies $\Psi_{2}$ ) and almost periodic function (that corresponds to frequencies $\Psi_{1} \cup \Psi_{3}$ )

The natural estimator of $\mu_{k} \quad(k=1,2, \ldots, T-1)$ based on sample $\left\{X_{1}, X_{2}, \ldots, X_{n}\right\}$ where $n=m T$ has the following form

$$
\hat{\mu}_{k, n}=\frac{1}{m} \sum_{j=1}^{m} X_{k+(j-1) T}
$$

The estimator $\hat{\boldsymbol{\mu}}_{n}=\left[\hat{\mu}_{1, n} \hat{\mu}_{2, n} \ldots \hat{\mu}_{T-1, n}\right]^{\prime}$ is asymptotically normally distributed with known variance covariance matrix.

Theorem 2.1 Assume that there exist constants $\delta>0, \Delta<\infty$ and $K<\infty$ such that
a) $\sup _{t \in Z}\left\|X_{t}\right\|_{2+\delta}<\Delta$,
b) $\sum_{k=0}^{\infty} \alpha(k)^{\frac{\delta}{2+\delta}} \leq K$.

Then

$$
\sqrt{m}\left(\hat{\boldsymbol{\mu}}_{n}-\boldsymbol{\mu}\right) \stackrel{d}{\rightarrow} \mathrm{N}_{T-1}(0, \Sigma)
$$

Proof. The proof can be found in the Appendix. 
The problem $\psi \in \Psi$ is equivalent to $|\tilde{m}(\psi)| \neq 0$ (or $\left|\tilde{m}^{\prime}(\psi)\right| \neq 0$ ). The natural estimator of Fourier coefficient based on sample $X_{1}, X_{2}, \ldots, X_{n}$ has the following form:

$$
\hat{m}_{n}(\psi)=\frac{1}{n} \sum_{t=1}^{n} X_{t} e^{-i \psi t} .
$$

This estimator is asymptotically normally distributed (see Lenart and Pipień, 2013a). The frequencies from the set $\Psi \backslash \Psi_{2}$ are estimated in nonparametric way using procedure introduced in Lenart and Pipień, 2013a. This procedure is based on subsampling approach applied for (nonstationary) almost periodically correlated time series (for more details see to Lenart, 2013; Lenart and Pipień, 2013a). Note that using similar technique the problem of testing seasonality effect (in nonparametric framework) in macroeconomic time series was considered in Lenart and Pipień, 2013b. The multivariate case of the model (1) was considered in Lenart and Pipień, 2015, where the testing procedure for common length of the business cycle was considered in selected European countries.

To show the impact of frequencies from the sets: $\Psi_{1}, \Psi_{2}, \Psi_{3}$ to the dynamic of time series we consider the following illustrative example.

Example 2.1 Let us consider time series $\left\{X_{t}: t \in Z\right\}$ of the form:

$$
X_{t}=\underbrace{\sum_{\psi \in \Psi} m(\psi) e^{i \psi t}}_{\mu(t)}+\eta_{t},
$$

where $\left\{\eta_{t}: t \in Z\right\}$ is zero mean time series with finite variance on integer line. It is assumed (in this example) that the considered time series is not necessary second order stationary. To explain the impact of the frequencies from the sets: $\Psi_{1}, \Psi_{2}, \Psi_{3}$ (under decomposition $\Psi=\Psi_{1}+\Psi_{2}+\Psi_{3}$ ) we consider four cases (T1-T4):

T1 $\Psi_{1}=\varnothing, \Psi_{3}=\varnothing, \Psi_{2}=\{2 k \pi / 12: k=1,2, \ldots, 5\}$, with $\eta_{t}=0.95 \eta_{t-1}+\varepsilon_{t}$ , where $\left\{\varepsilon_{t}: t \in Z\right\}$ is gaussian white noise with zero mean and variance equal one. In this case only seasonal pattern (with period $T=12$ ) is present in mean function.

T2 $\Psi_{1}=\{0.15\}, \quad \Psi_{3}=\varnothing, \quad \Psi_{2}=\{2 k \pi / 12: k=1,2, \ldots, 5\}, \quad$ with $\eta_{t}=\left(0.95-0.5\left|\sin \left(\frac{\pi t}{6}\right)\right|\right) \eta_{t-1}+\varepsilon_{t}$, where $\left\{\varepsilon_{t}: t \in \mathrm{Z}\right\}$ is gaussian white noise with zero mean and variance equal one. In this case considered 
time series has periodic autocovariance function with period equal to 12 and seasonal pattern (in mean function) with length of the season equal 12. In the mean function we put additional frequency (equal to 0.15 ) that corresponds to cyclical fluctuations with period approx. to 3.5 years.

T3 $\Psi_{1}=\varnothing, \quad \Psi_{3}=\{2 \pi / 3+0.1\}, \quad \Psi_{2}=\{2 k \pi / 12: k=1,2, \ldots, 5\}, \quad$ with $\eta_{t}=-0.6 \eta_{t-1}+\varepsilon_{t}$, where $\left\{\varepsilon_{t}: t \in \mathrm{Z}\right\}$ is gaussian white noise with zero mean and variance equal one. In this case the additional frequency $2 \pi / 3+0.1$ was put in mean function.

T4 $\Psi_{1}=\{0.15\}, \quad \Psi_{3}=\{2 \pi / 3+0.1\}, \quad \Psi_{2}=\{2 k \pi / 12: k=1,2, \ldots, 5\}, \quad$ with $\eta_{t}=0.5 \eta_{t-1}+\varepsilon_{t}$, where $\left\{\varepsilon_{t}: t \in Z\right\}$ is gaussian white noise with zero mean and variance equal one. In this case we consider the case where both set: $\Psi_{1}$ and $\Psi_{3}$ are not empty.
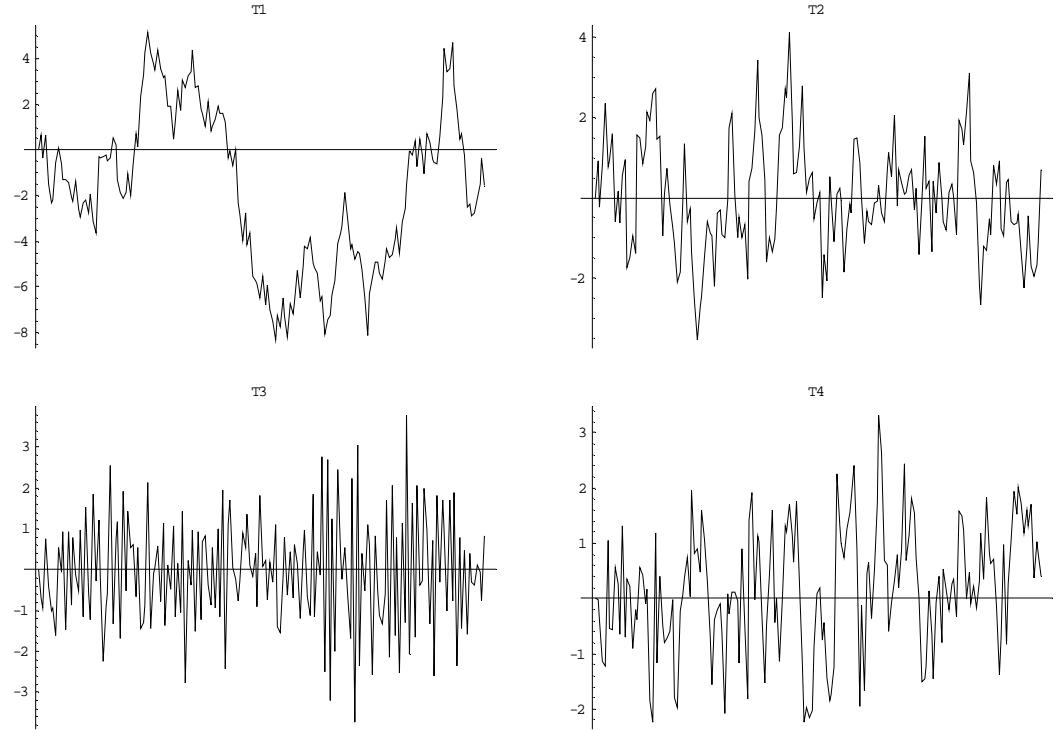

Figure 1. The realizations of $\left\{\eta_{t}: t \in Z\right\}$ for considered cases, $n=180$ 

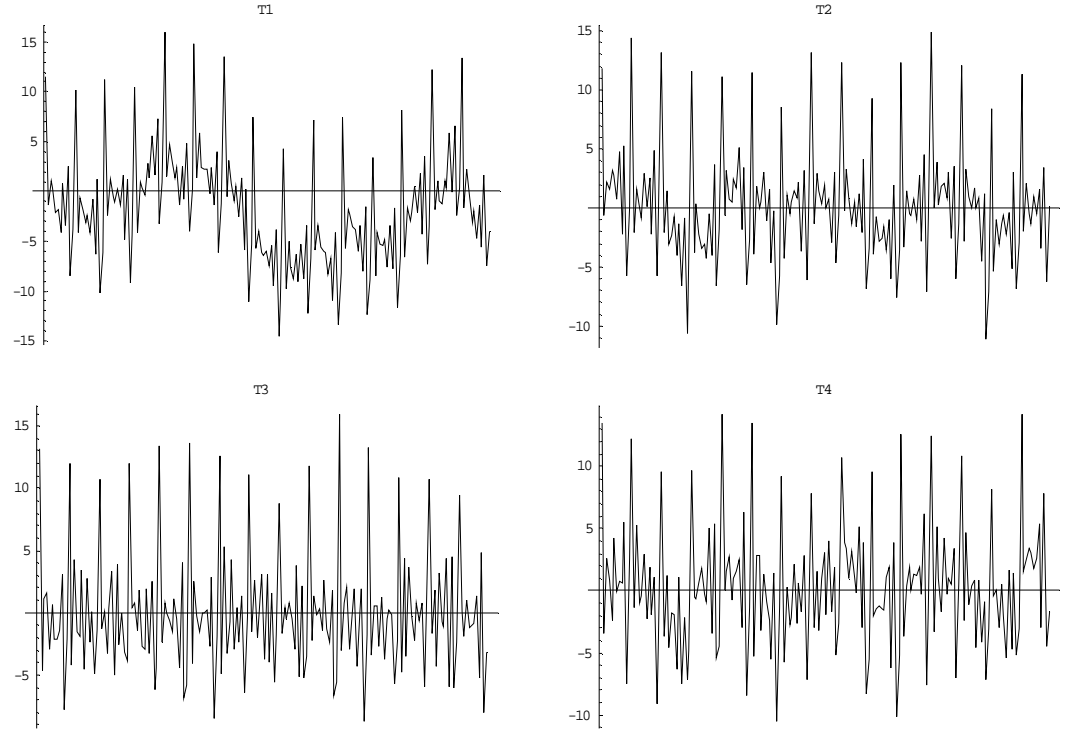

Figure 2. The realizations of $\left\{X_{t}: t \in Z\right\}$ for considered cases, $n=180$
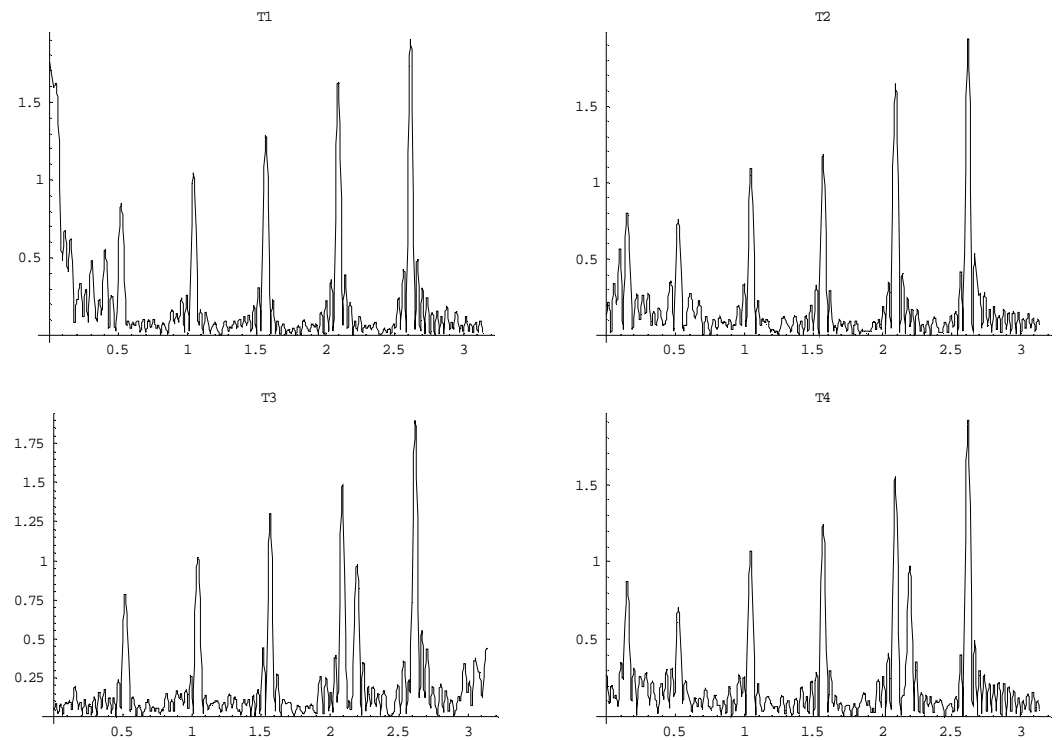

Figure 3. The estimated magnitude of Fourier transforms $\left|\hat{m}_{n}(\psi)\right|$ for considered cases, $\psi \in[0, \pi]$ 
In all cases we clearly observe peaks at seasonal frequencies $\{2 k \pi 12: k=1,2, \ldots, 5\}$ (see Figure 3). Note that the Fourier coefficient at frequency $\pi$ equals zero. In the case T1 considered time series is second order stationary and the peak close to zero corresponds to second order properties of considered time series. In the case T2 and T4 the peak at frequency 0.15 is observed while the frequency from the set $\Psi_{3}(2 \pi / 3+0.1)$ can be recognized easily only in the case $\mathrm{T} 4$.

\section{Empirical analysis}

We consider production in industry - monthly data (mining and quarrying; manufacturing; electricity, gas, steam and air conditioning supply) from Feb 2000 to Dec 2014. We consider monthly and annual rate of change (gross data and data adjusted by working days). The production in industry for thirty countries were considered (with ordinal numbers): Belgium (1); Bulgaria (2); Czech Republic (3); Denmark (4); Germany (5); Estonia (6); Greece (7); Spain (8); France (9); Croatia(10); Italy (11); Cyprus (12); Latvia (13); Lithuania (14); Luxembourg (15); Hungary (16); Malta (17); Netherlands (18); Austria (19); Poland (20); Portugal (21); Romania (22); Slovenia (23); Slovakia (24); Finland (25); Sweden (26); United Kingdom (27); Norway (28); Former Yugoslav Republic of Macedonia, (29); Serbia (30);

\subsection{Graphical methods for frequency identification}

In this section we introduce two graphical methods (visual methods) for recognise cyclical fluctuations. The first method is based directly on observing the estimates of magnitude of Fourier coefficient $|m(\psi)|$ (as a function of frequency). In this graphical method we try to recognise maximum local values (peaks). The second method is based on Theorem 2.1. In this method we consider only the m-o-m change cantered at each month by appropriate estimates $\hat{\mu}_{k, n}$ of seasonal coefficient $\mu_{k}$. The aim of this method is to recognize any cyclical fluctuations around estimates $\hat{\mu}_{k, n}$.

In the first step we consider monthly rate of change (gross data - data not adjusted by working days). For each considered economies the test presented in Lenart and Pipień, 2013b reject the null hypothesis concerning empty set of seasonal frequencies $\Psi_{2}$. In this case the estimated magnitude of Fourier coefficients (for $\psi \in[0, \pi]$ ) clearly support the existence of the peaks at seasonal frequencies (see Figure 8). The peaks at frequencies that correspond to business cycle fluctuations are not observed jointly for consi- 

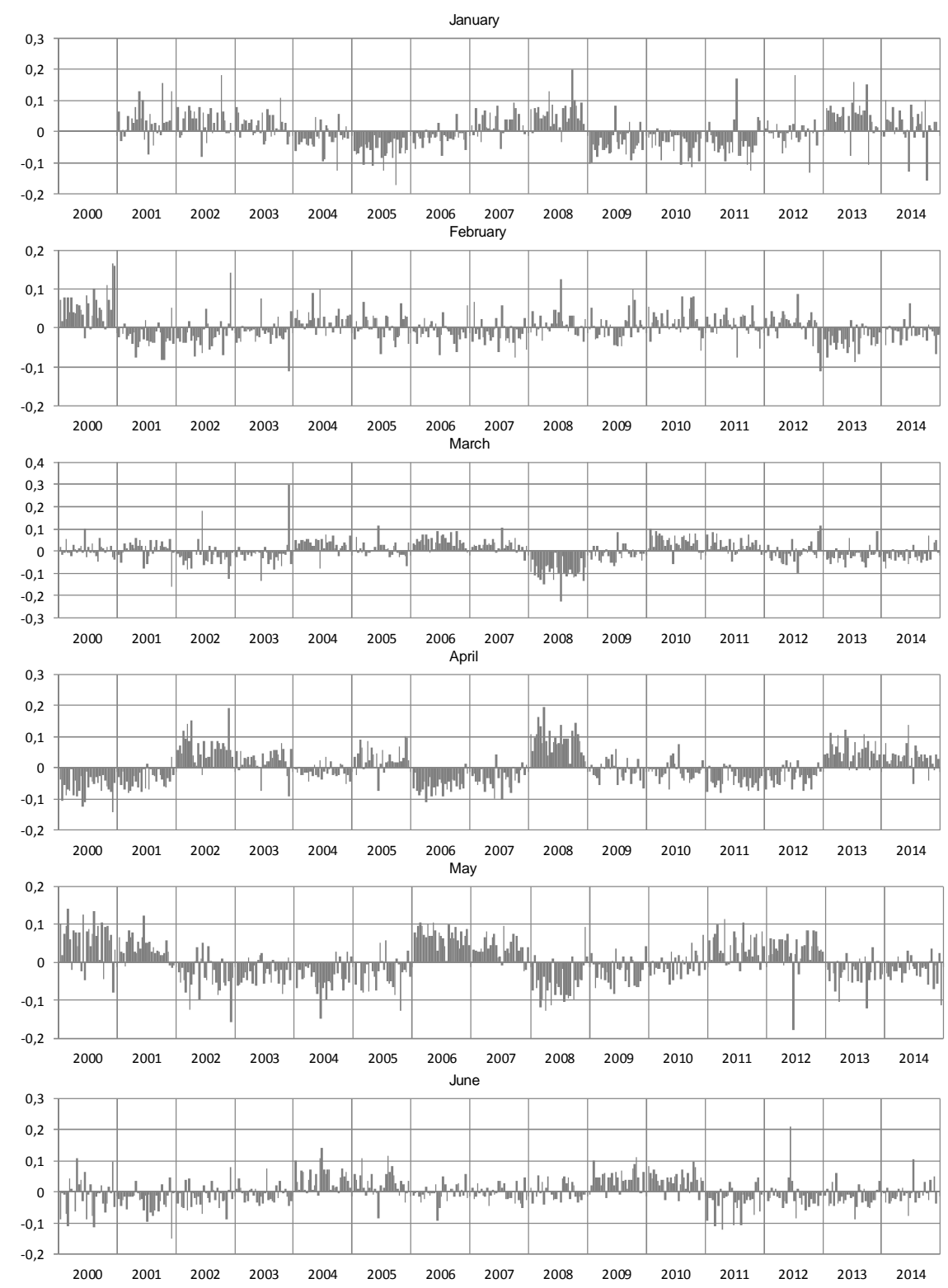

Figure 4. Cantered seasonal values at their estimates (January-June). Data not adjusted by working days 

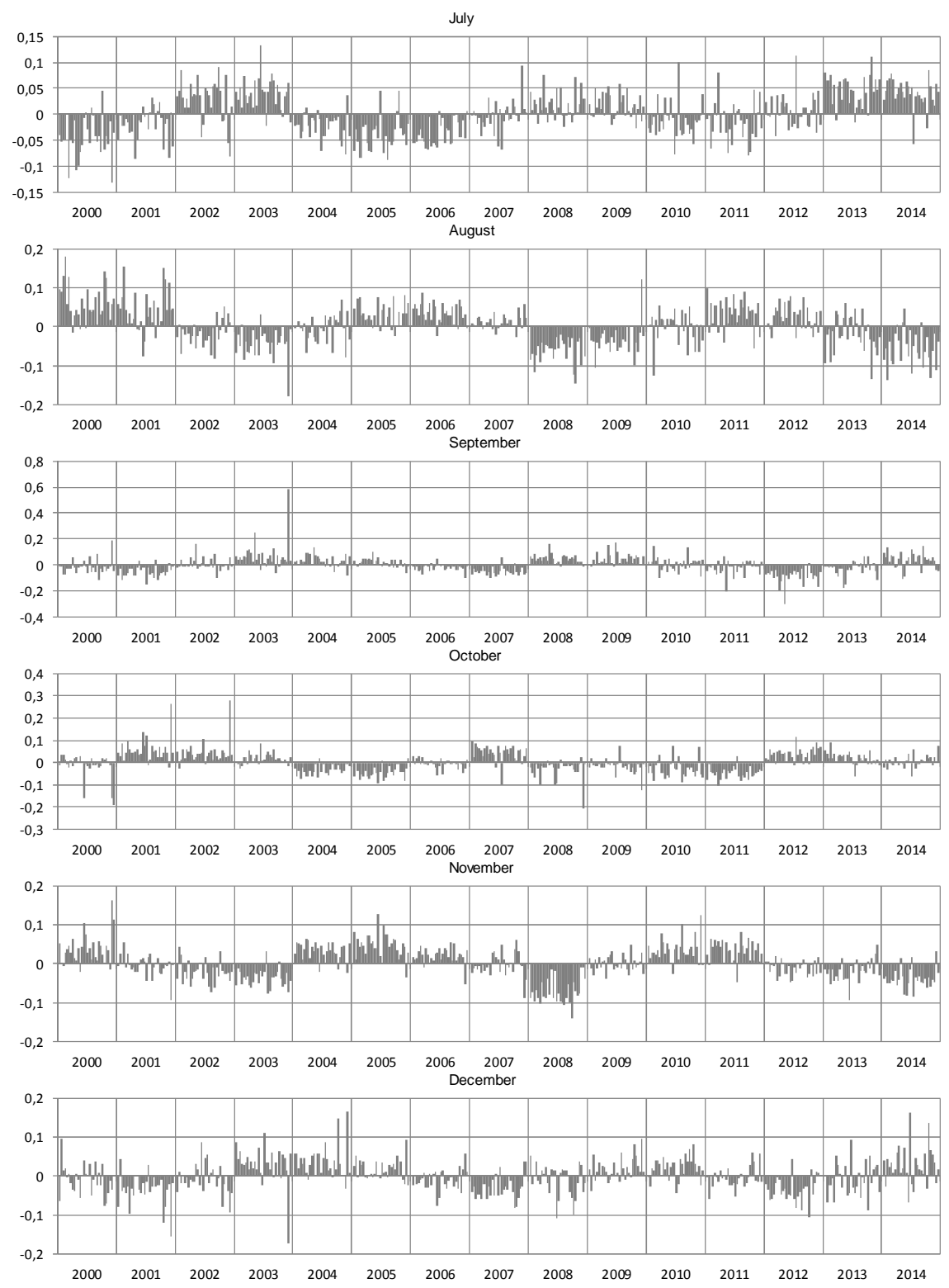

Figure 5. Cantered seasonal values at their estimates (July-December). Data not adjusted by working days

Dynamic Econometric Models 15 (2015) 27-47 

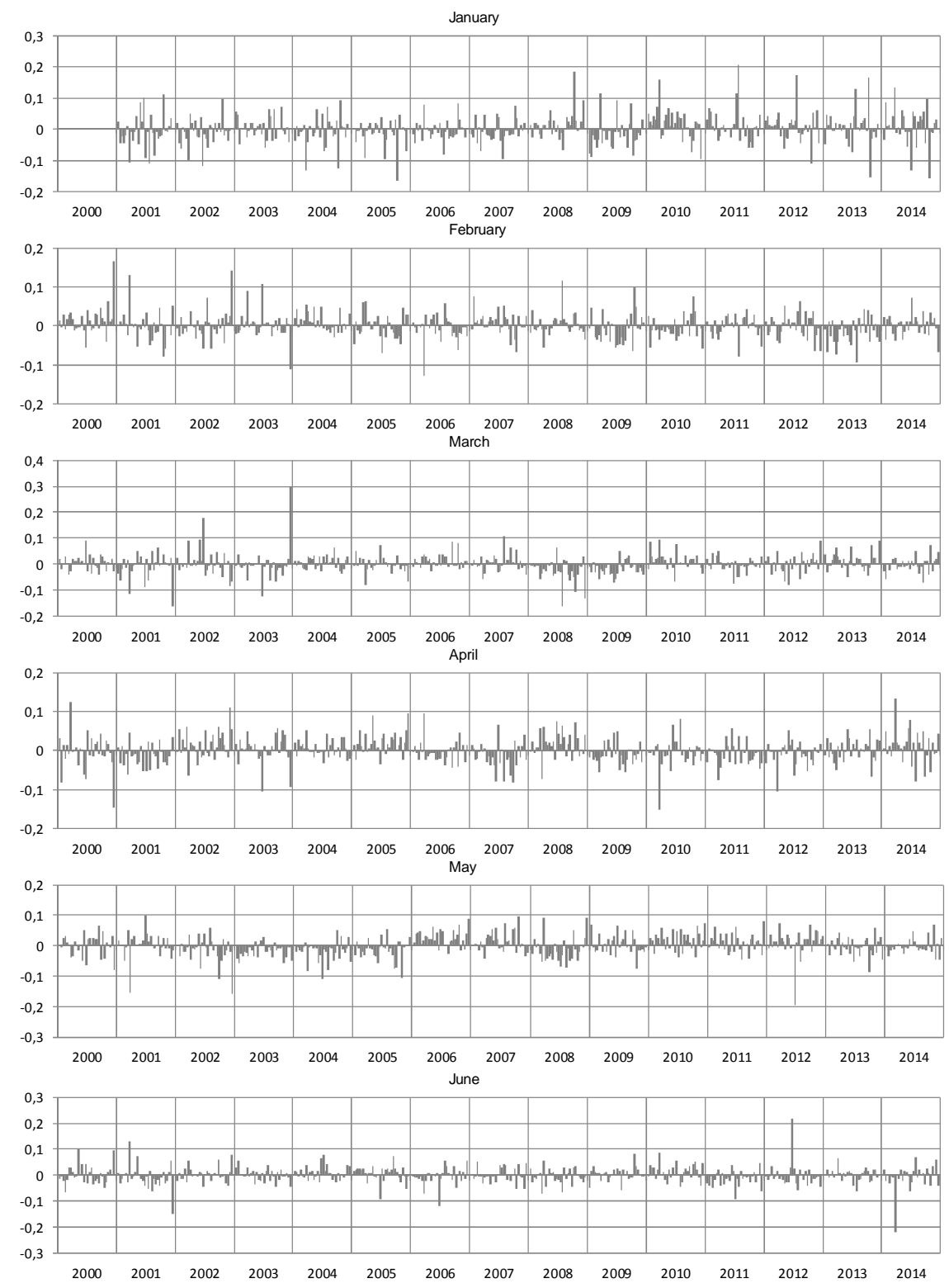

Figure 6. Cantered seasonal values at their estimates (January-June). Data adjusted by working days 

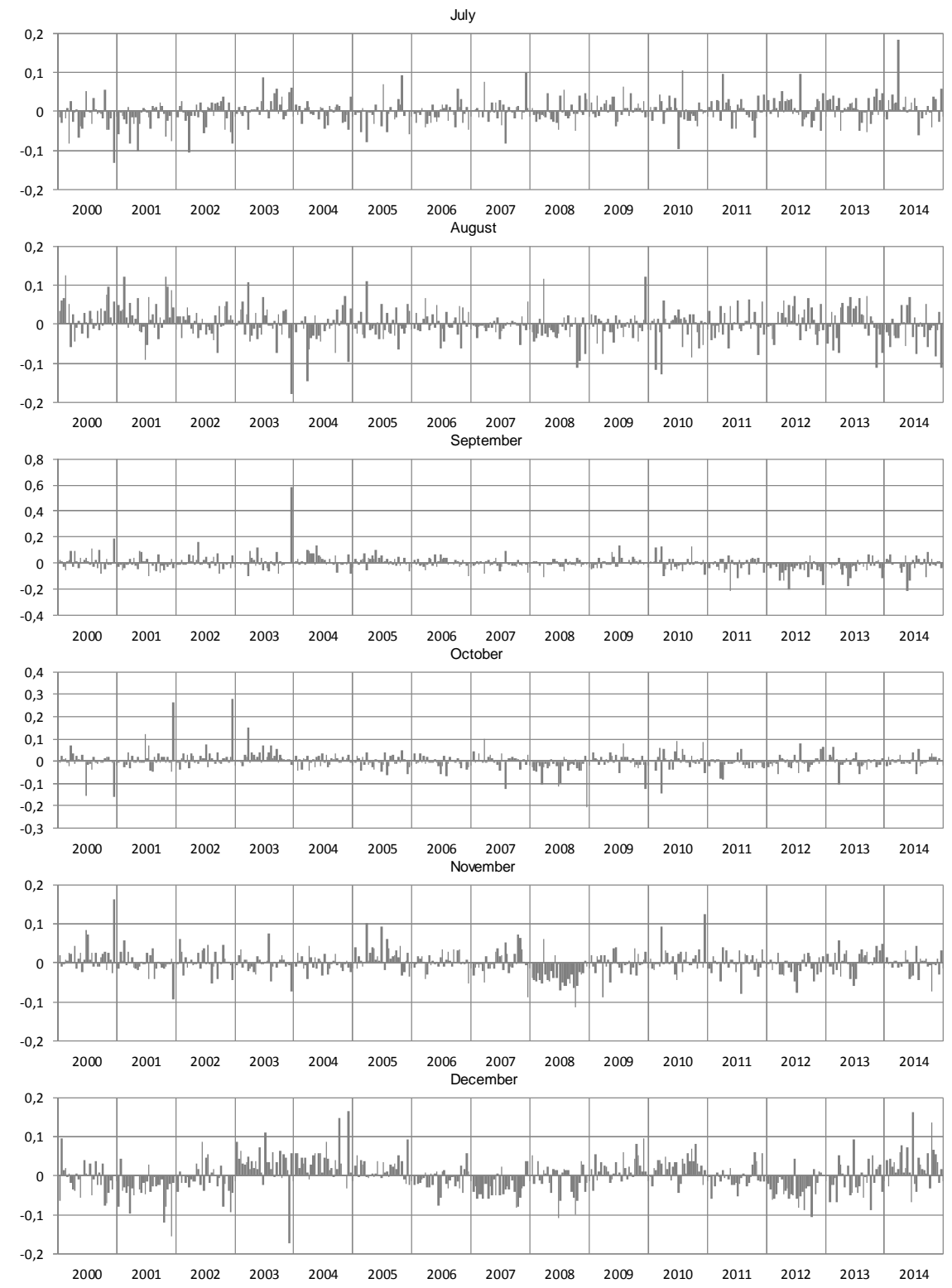

Figure 7. Cantered seasonal values at their estimates (July-December). Data adjusted by working days

Dynamic Econometric Models 15 (2015) 27-47 
dered countries. But the additional frequency that belongs to the set $\Psi_{3}$ is clearly observed. This frequency is approx. to 2.19 and is connected with trading-day effect in considered data. This frequency is a main theoretical frequency associated with a monthly trading-day effect (see Ladiray, 2012, page 262). The peak at this frequency is observed for almost all considered data sets also in the case of annual rate of change (see Figure 10). When the estimates of Fourier coefficient $\left|\hat{m}_{n}(\psi)\right|$ are considered for data adjusted by working days (monthly and annual rate of change) the peaks at frequency approx. 2.19 are not observed.

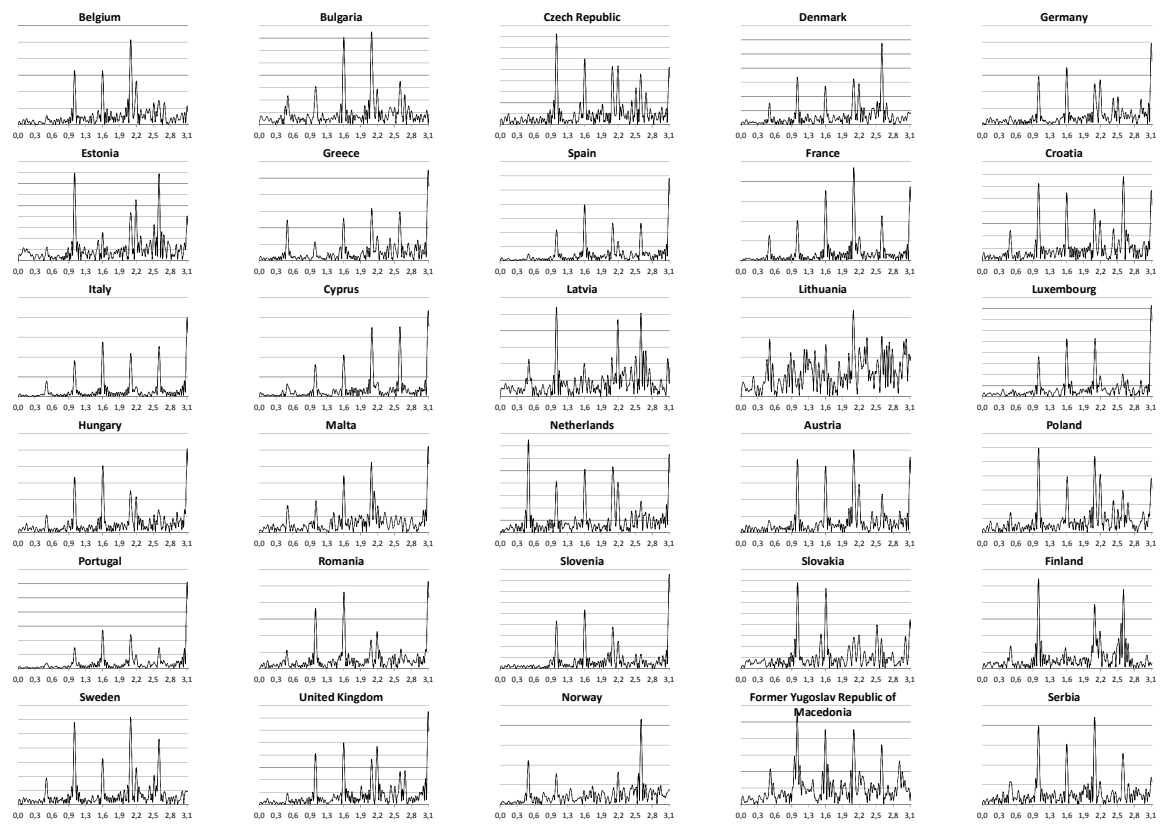

Figure 8. The estimated magnitude of Fourier transforms $\left|\hat{m}_{n}(\psi)\right|$ for m-o-m data - not adjusted by working days, $\psi \in[0, \pi]$

Using second graphical method, the trading-day effect is clearly observed. The Figure 4 and 5 presents the results of mean subtraction separately at each different month. Obtained results clearly show the common fluctuations (around their estimates) for almost each countries. Note that the phase of this fluctuations (above or below mean) differs in different consecutive month at the same year (compare for example April with May in the same years). Therefore, such fluctuation seems not to be the effected by 
business cycles. Finally, these fluctuations are not observed for the data after working day adjustment (see Figure 6 and 7).
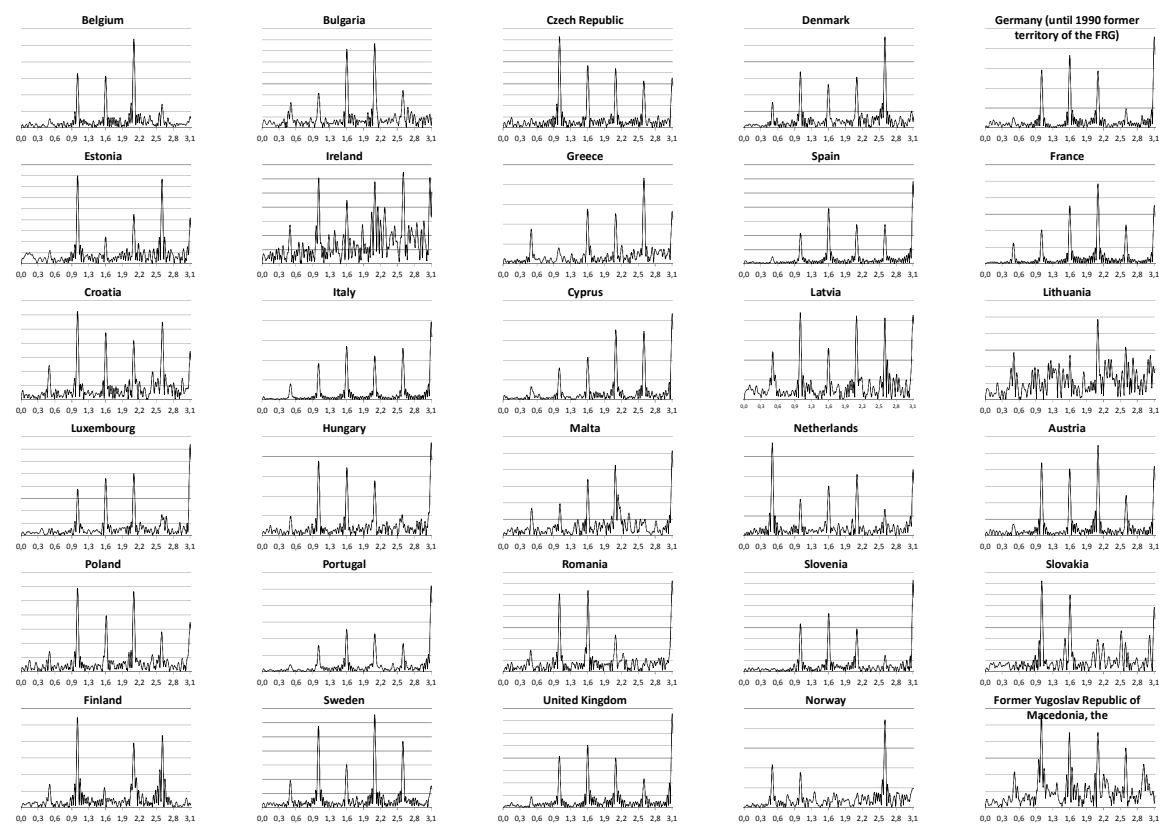

Figure 9. The estimated magnitude of Fourier transforms $\left|\hat{m}_{n}(\psi)\right|$ for m-o-m data - adjusted by working days, $\psi \in[0, \pi]$

\subsection{Testing for frequency significance}

In this part we consider formal statistical tools to detect significant frequencies in mean function for considered data sets. We use nonparametric test presented in Lenart, 2013; Lenart and Pipień, 2013a and we compare our results with parametric estimates obtained by so-called contraction method (CM in short) introduced by Li and Song, 2002. Based on Lenart, 2013; Lenart and Pipień, 2013a we consider the following testing problem:

$$
\begin{aligned}
& H_{0}: \quad \psi \notin \Psi \\
& H_{1}: \quad \psi \in \Psi
\end{aligned}
$$


with the test statistics $\sqrt{n}\left|\hat{m}_{n}(\psi)\right|$ and critical values of the test calculated by subsampling approach (we take $b=2.5 \sqrt{n}$ ). Based on the test (8) and estimation procedure proposed in Lenart, 2013 the set of frequency was estimated. In our analysis we consider both: gross data and data adjusted by working days for both m-o-m and y-o-y case.

To compare our results we use parametric CM. In this case the number of iterations is 100 on the interval $(0, \pi)$ (with the resolution equal to 300 ). The bandwidth parameters are: $\eta_{1}=0.96$ for $m<20, \eta_{1}=0.98$ for $m<40$, $\eta_{1}=0.99$ for $m<60, \eta_{1}=0.995$ for $m<80$.
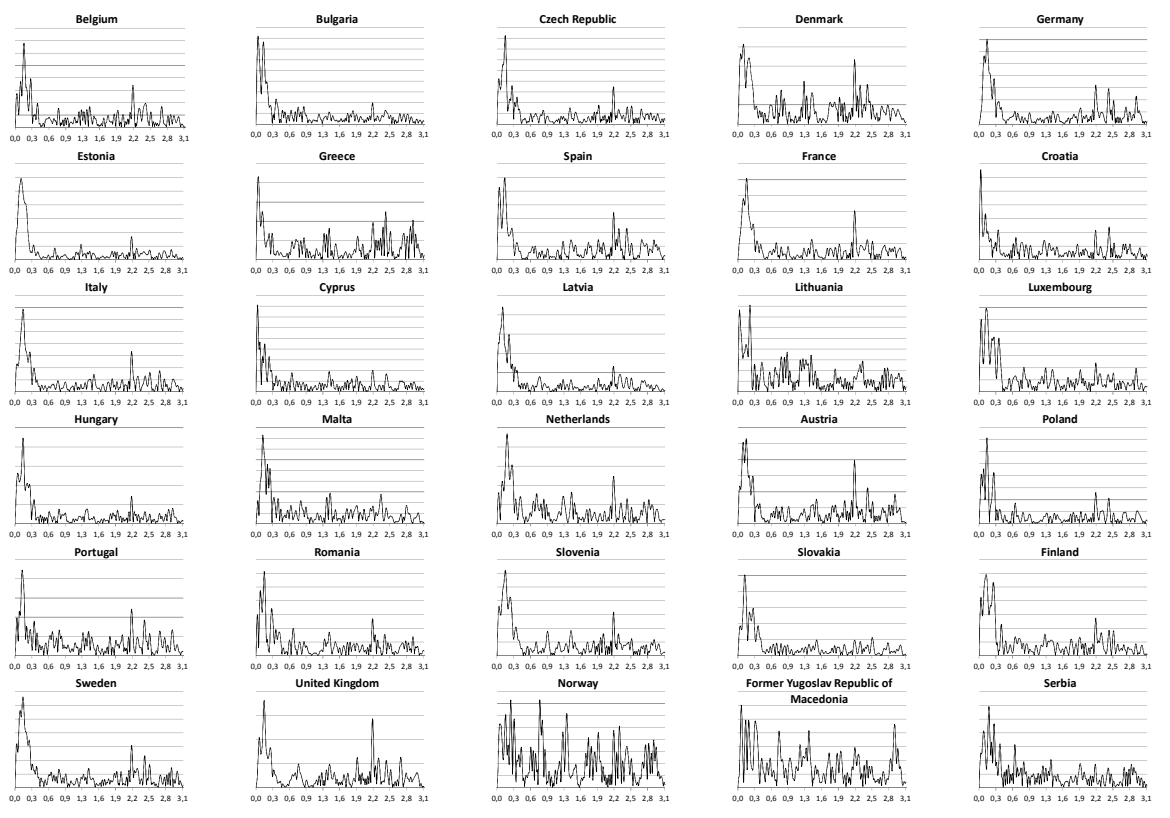

Figure 10. The estimated magnitude of Fourier transforms $\left|\hat{m}_{n}(\psi)\right|$ for y-o-y data not adjusted by working days, $\psi \in[0, \pi]$

In the case of m-o-m data sets method based on subsampling procedure clearly confirm the existence of seasonal frequencies for data not adjusted and adjusted by working days (see Figure 12 (a)-(b)). In the case of data not adjusted by working days the significant frequency approx. 2.19 is observed for most considered countries, while in the case of data adjusted by working days this frequency is clearly not significant on considered significance level. In the case of y-o-y data sets not adjusted by working days the method 
based on subsampling procedure also confirm the significance of frequency approx. 2.19 for most considered countries (see Figure 12 (c)-(d)). In the case of data adjusted by working days the frequency approx. 2.19 is clearly not significant (under considered significance level).
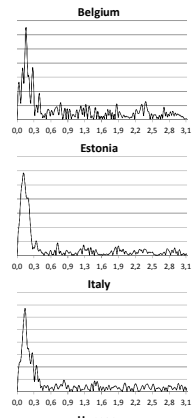

Hungary
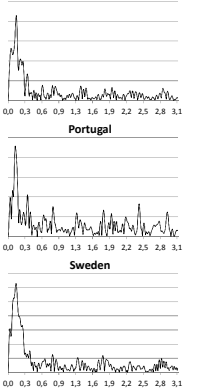

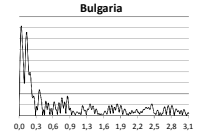

Grece

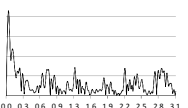

Cyprus

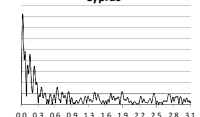

Malta
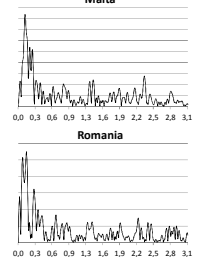

United Kingdom

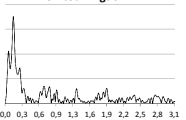

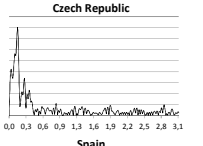
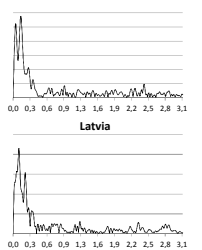

Netherlands

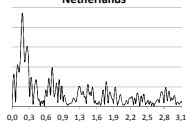

Sovenia
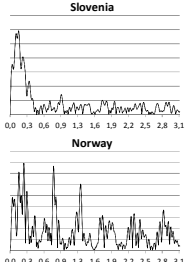
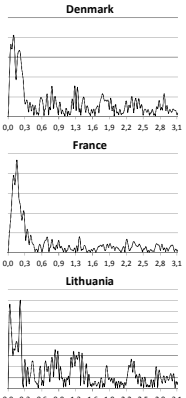

Austria

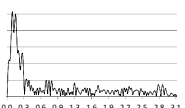

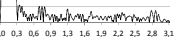
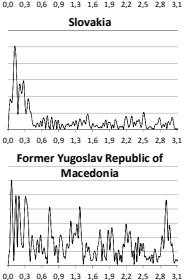
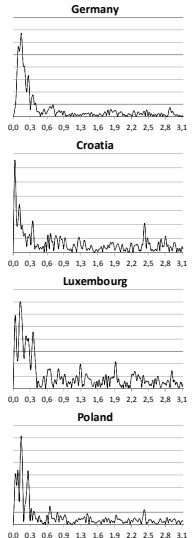

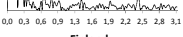

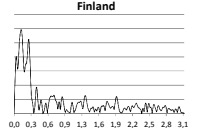

Serbia

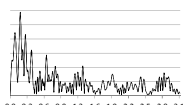

Figure 11. The estimated magnitude of Fourier transforms $\left|\hat{m}_{n}(\psi)\right|$ for y-o-y data adjusted by working days, $\psi \in[0, \pi]$

The procedure proposed by $\mathrm{Li}$ and Song, 2002 gives similar results for frequency approx. 2.19. But for the frequency that corresponds to business cycle fluctuations the CM gives different results (in comparison with method based on subsampling). In the case of CM for almost all countries the frequencies that correspond to business cycle fluctuations are included in estimated set. It should be emphasized that in the case of subsampling the nonparametric test is applied - based on resampling procedure, while in the case of CM the only estimation procedure (based on parametric model) is used without any test procedure (see estimation procedure in $\mathrm{Li}$ and Song, 2002). Therefore Figure 12 a)-d) presents results of testing procedure while e)-f) only results of the estimation procedure. 


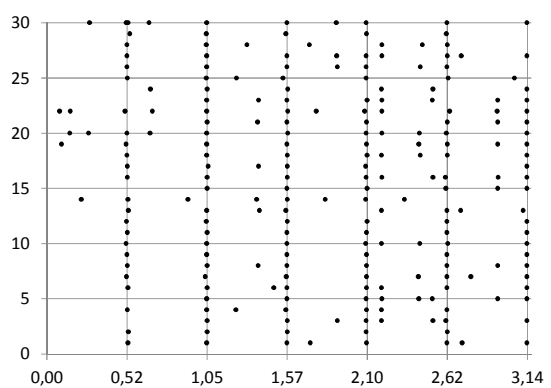

(a) subsampling for m-o-m data, not adjusted by working days

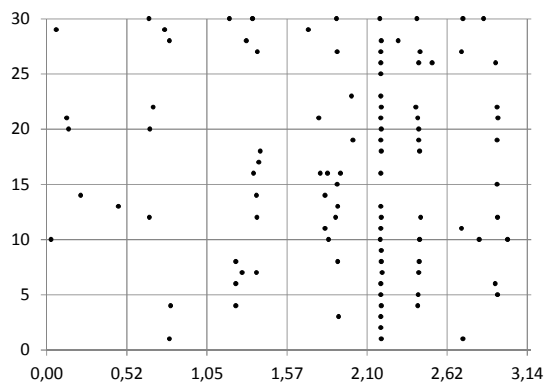

(c) subsampling for $y-0-y$ data, not adjusted by working days

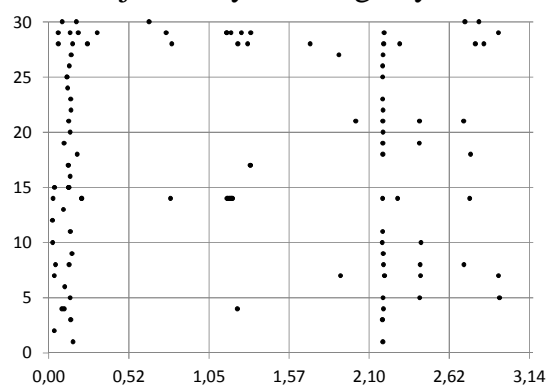

(e) CM for y-o-y, data not adjusted by working days

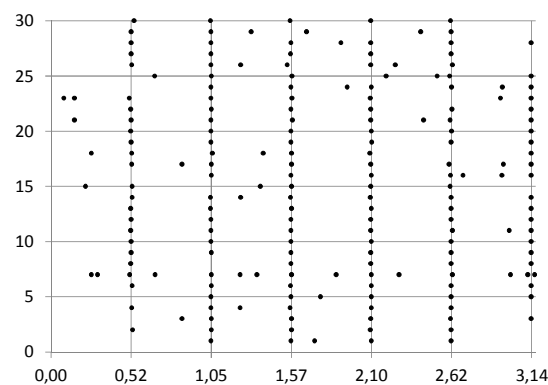

(b) subsampling for m-o-m data; adjusted by working days

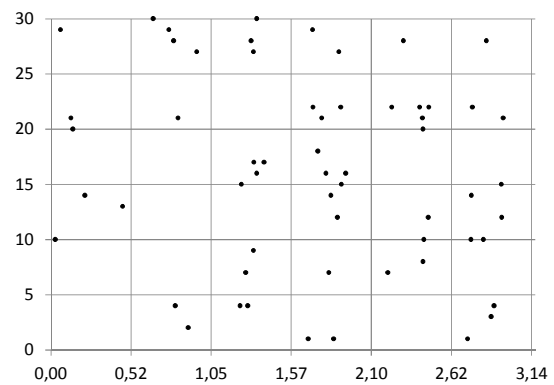

(d) subsampling for $y-0-y$ data, adjusted by working days

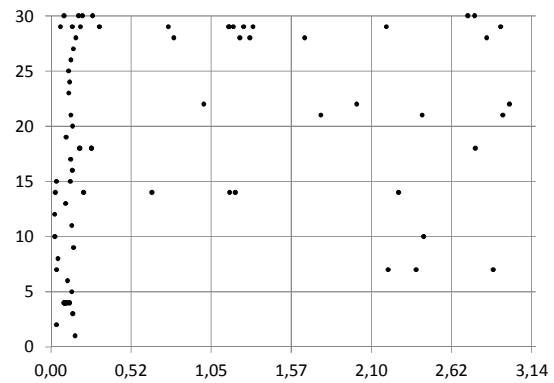

(f) CM for y-o-y, data adjusted by working days

Figure 12. (a)-(d) Estimated frequency sets (dots). Horizontal axis - estimated frequency; Vertical axis - the ordinal number of considered country. (a)-(d) - nonparametric approach based on subsampling methodology introduced in Lenart, 2013; (e)-(f) CM introduced by Li and Song, 2002 


\section{Conclusions}

The discrete spectral analysis can be useful supplementary analysis to usual spectral analysis based on continuous spectrum. Presented methods (graphical and formal statistical test) are useful in recognizing frequencies that corresponds to business fluctuations, seasonal fluctuations and tradingday effects. One of the main open problems is a formal statistical test for trading-day effect. Corresponding test for business fluctuations was introduced in Lenart and Pipień, 2013a and in Lenart and Pipień, 2013b for seasonal pattern. Note that in the literature the popular so-called visual test (see Ladiary, 2012) for trading-day frequencies plays a central role.

\section{Appendix}

Proof of the Theorem 2.1. We start from auxiliary Lemma.

Lemma A.1 If assumptions of the Theorem 2.1 hold then for any $k_{1}, k_{2} \in\{1,2, \ldots, T-1\}$ the limit

$$
\lim _{m \rightarrow \infty} E\left(\frac{1}{m} \sum_{j_{1}=1}^{m} \sum_{j_{2}=1}^{m}\left(X_{k_{1}+\left(j_{1}-1\right) T}-\mu_{k_{1}}\right)\left(X_{k_{2}+\left(j_{2}-1\right) T}-\mu_{k_{2}}\right)\right)
$$

exists and it's finite.

Proof of the Lemma. Notice that

$$
\begin{aligned}
& E\left(\frac{1}{m} \sum_{j_{1}=1}^{m} \sum_{j_{2}=1}^{m}\left(X_{k_{1}+\left(j_{1}-1\right) T}-\mu_{k_{1}}\right)\left(X_{k_{2}+\left(j_{2}-1\right) T}-\mu_{k_{2}}\right)\right) \\
= & \frac{1}{m} \sum_{j_{1}=1}^{m} \sum_{j_{2}=1}^{m} \operatorname{cov}\left(X_{k_{1}+\left(j_{1}-1\right) T}, X_{k_{2}+\left(j_{2}-1\right) T}\right) \\
= & \sum_{\tau=-m+1}^{m-1}\left(1-\frac{|\tau|}{m}\right) \operatorname{cov}\left(X_{k_{1}}, X_{k_{2}+\tau T}\right)
\end{aligned}
$$

Using now Theorem 3, page 9 form Doukhan, 1994 we get inequality $\left|\operatorname{cov}\left(X_{k_{1}}, X_{k_{2}+\tau T}\right)\right| \leq 8 \Delta^{2} \alpha^{\frac{\delta}{2+\delta}}\left(\left|k_{2}-k_{1}+\tau T\right|\right)$. Since (10) is a Feyèr's sum at a point $x_{0}=0$ the limit for $m \rightarrow \infty$ exists. This finish the proof of the Lemma. 
We use the same technique as presented in Lenart, 2013 in proof of Theorem 2.1. Let us consider the decomposition:

$$
\sqrt{m}\left(\hat{\boldsymbol{\mu}}_{n}-\boldsymbol{\mu}\right)=\underbrace{\sqrt{m}\left(\hat{\boldsymbol{\mu}}_{n}-E\left(\hat{\boldsymbol{\mu}}_{n}\right)\right)}_{r_{1}(n)}+\underbrace{\sqrt{m}\left(E\left(\hat{\boldsymbol{\mu}}_{n}\right)-\boldsymbol{\mu}\right)}_{r_{2}(n)} .
$$

Using the same arguments it is sufficient to show the convergence:

$$
r_{1}(n) \stackrel{d}{\rightarrow} \mathrm{N}_{T-1}(0, \Sigma)
$$

and

$$
r_{2}(n) \rightarrow 0 .
$$

To show (11) it is enough to use the Cramér-Wold device, Theorem 3.3.1 from Guyon, 1995 and Lemma 5.1. To prove (12) notice that for any $k=1,2, \ldots, T-1$ we have

$$
\begin{aligned}
\sqrt{m}\left|E\left(\hat{\mu}_{k, n}\right)-\mu_{k}\right| & =\sqrt{m}\left|\frac{1}{m} \sum_{j=1}^{m} E\left(X_{k+(j-1) T}\right)-\mu_{k}\right| \\
& =\frac{1}{\sqrt{m}}\left|\sum_{j=1}^{m} \tilde{\mu}_{2}(k+(j-1) T)\right| \\
& =\frac{1}{\sqrt{m}}\left|\sum_{j=1}^{m} \sum_{\psi \in \Psi \Psi \Psi_{2}} \tilde{m}(\psi) e^{i \psi(k+(j-1) T)}\right| \\
& \leq \frac{1}{\sqrt{m}} \sum_{\psi \in \Psi \Psi \Psi_{2}}\left|\tilde{m}(\psi) \frac{2}{1-e^{i \psi T} \mid}\right|=O\left(\sqrt{\frac{1}{m}}\right) \rightarrow 0 .
\end{aligned}
$$

This completes the proof.

\section{References}

Croux, Ch., Forni, M., Reichlin, L. (2001), A measure of covomement for economic variables: theory and empirics, The Review of Ecomonics and Statistics, 83(2), 232-241, DOI: http://dx.doi.org/10.1162/00346530151143770.

Doukhan, P. (1994), Mixing: Properties and Examples, Springer-Verlag, New York,

Ftiti, Z. (2010), The macroeconomic performance of the inflation targeting policy: An approach based on the evolutionary co-spectral analysis (extension for the case of a multivariate process), Economic Modelling, 27, 468-476.

Guyon, X. (1995), Random Fields on a Network. Springer-Verlag, New York.

Hamilton, J. D., (1994), Time Series Analysis, Princeton University Press, New Jersey. 
Hurd, H., Gerr, L. (1991), Graphical methods for determining the presence of periodic correlation, Journal of Time Series Analysis, 12(4), 337-350, DOI: http://dx.doi.org/10.1111/j.1467-9892.1991.tb00088.x.

Ladiray, D. (2012), Theoretical and real trading-day frequencies, in Bell W.R., Holan S.H. and McErloy T.S. (ed.), Economic time Series: Modeling and Seasonality, 255-279. DOI: http://dx.doi.org/10.1201/b11823-16.

Lenart, Ł, Pipień, M. (2013a), Almost periodically correlated time series in business fluctuations analysis, Acta Physica Polonica A, 123(3), 567-583, DOI: http://dx.doi.org/10.12693/APhysPolA.123.567.

Lenart, Ł, Pipień, M. (2013b), Seasonality revisited - statistical testing for almost periodically correlated processes, Central European Journal of Economic modelling and Econometrics, 5, 85-102.

Lenart, Ł, Pipień, M. (2015), Testing the common length of the business cycles with discrete spectral analysis and subsampling approach, Submited to Journal of Time Series Analysis.

Lenart, Ł. (2011), Asymptotic distributions and subsampling in spectral analysis for almost periodically correlated time series, Bernoulli, 17(1), 290-319, DOI: http://dx.doi.org/10.3150/10-BEJ269.

Lenart, Ł. (2013), Non-parametric frequency identification and estimation in mean function for almost periodically correlated time series, Journal of Multivariate Analysis, 115, 252-269. DOI: http://dx.doi.org/10.1016/j.jmva.2012.10.006.

Li, T. H., Song, K. S. (2002), Asymptotic analysis of a fast algorithm for efficient multiple frequency estimation, IEEE Transactions on Information Theory, 48(10), 2709 - 2720.

McAdam, P., Mestre, R. (2008), Evaluating macro-economic models in the frequency domain: A note. Economic Modelling, 25, 1137-1143.

Metz, R. (2009), Comment on "Stock markets and business cycle comovement in Germany before world war I: Evidence from spectral analysis", Journal of Macroeconomics, 31, 58-67, DOI: http://dx.doi.org/10.1016/j.jmacro.2008.01.004.

Orlov, A. G. (2006), Capital controls and stock market volatility in frequency domain, Economics Letters, 91, 222-228, DOI: http://dx.doi.org/10.1016/j.econlet.2005.09.014.

Orlov, A. G. (2009), A cospectral analysis of exchange rate comovements during Asian financial crisis, Journal of International Financial Markets, Institutions and Money, 19, 742-758, DOI: http://dx.doi.org/10.1016/j.intfin.2008.12.004.

Pakko, M. R. (2004), A spectral analysis of the cross-country consumption correlation puzzle, Economics Letters, 84, 341-347.

Priestley, M. B. (1981), Spectral Analysis and Time Series, Academic Press, London, DOI: http://dx.doi.org/10.2307/2983035.

Uebele, M., Ritschl, A. (2009), Stock markets and business cycle comovement in Germany before World War I: Evidence from spectral analysis, Journal of Macroeconomics, 31, $35-57$.

\section{Analiza spektrum dyskretnego na przykładzie produkcji przemysłowej w wybranych krajach europejskich}

$\mathrm{Z}$ a r y s tre ś c i. Artykuł przedstawia analizę spectrum dyskretnego dla produkcji przemysłowej wybranych gospodarek europejskich. Analizie poddano dane o częstotliwości miesięcznej. Przyjęto założenie o prawie okresowej postaci funkcji wartości oczekiwanej wokół

Dynamic Econometric Models 15 (2015) 27-47 
długookresowej tendencji rozwojowej. W artykule przedstawiono dwie metody graficzne identyfikacji wahań cyklicznych (koniunkturalnych, sezonowych oraz wynikających z różnej liczby dni roboczych w miesiącu). Pierwsza z nich bazuje na identyfikacji najwyższych wartości estymatora współczynnika Fouriera, jako funkcji częstotliwości. Metoda ta może być stosowana dla miesięcznej oraz rocznej stopy wzrostu. Druga metoda graficzna może być zastosowana jedynie dla miesięcznej stopy wzrostu. Bazuje ona na graficznej identyfikacji wahań cyklicznych w danych po odjęciu od nich wartości estymatora współczynników sezonowych. W kolejnej części artykułu przedstawiono wyniki formalnego testu istotności częstotliwości w oparciu o prace: Lenart, 2013 oraz Lenart oraz Pipień, 2013a. Warto zaznaczyć, iż test ten pozwolił na formalne zidentyfikowanie częstotliwości korespondującej do wahań związanych z elektem różnej liczby dni roboczych w kolejnych miesiącach roku.

S ło w a k 1 u c z o w e: analiza spectrum dyskretnego, funkcja prawie okresowa, identyfikacja częstotliwości, test graficzny. 
